\title{
Sustentabilidade: nova percepção jurídica e os reflexos de sua aplicabilidade no cotidiano da Administração Pública
}

\author{
Sustainability: a new legal perception and the reflects of its applicability on \\ the daily life of Public Administration
}

Karine Borges de Liz

Raulino Jacó Brüning

\begin{abstract}
Resumo: O estudo da sustentabilidade enquanto realidade jurídica para além do Direito Ambiental é ainda incipiente. Muito embora seja dos temas da atualidade um dos mais instigantes, com reflexos imediatos e profundos no cotidiano da sociedade e das instâncias administrativas estatais. $\mathrm{O}$ presente ensaio propõe-se apresentar a discussão jurídica desse assunto nos dias correntes, demonstrando como o ordenamento jurídico tem se amoldado em razão desta realidade, principalmente no âmbito da Administração Pública. Por conseguinte, a demonstração do posicionamento do Tribunal de Contas da União sobre a temática e a exposição do atual norteamento do Conselho Nacional de Justiça sobre o assunto fazem-se necessários para uma melhor compreensão deste importante tema.
\end{abstract}

Palavras-chave: Sustentabilidade. Administração Pública. Tribunal de Contas da União. Conselho Nacional de Justiça.

\begin{abstract}
The study of sustainability perceived as a legal reality beyond the environmental law is still incipient, even though it is a current theme. It is also considered one of the most exciting topics, causing immediate and profound consequences in the daily experiences of society, and state administrative bodies. This paper aims to present a legal discussion of this matter nowadays, demonstrating how the law has been shaped by this reality, especially in the field of Public Administration. Therefore, the position of the Brazilian Court of Auditors on this subject as well as the current National Council of Justice guidelines on this subject are exposed in order to enable a better understanding of this important topic.
\end{abstract}

Keywords: Sustainability. Public Administration. Brazilian Court of Auditors. National Council of Justice.

Artigo recebido em 11 mar. 2016 e aprovado em 28 abr. 2016. 


\section{Introdução}

A ciência jurídica tem voltado sua atenção para um tema que vem ganhando importância dada a realidade vigente: a sustentabilidade como conceito jurídico que avança para além da noção de sustentabilidade ambiental. As razões para a investigação do assunto sob esse aspecto são diversas e graves.

Há, em termos gerais, grande tensão mundial gerada por desequilíbrios e desentendimentos de toda ordem - social, econômico, jurídico, cultural, ambiental etc. Por conseguinte, a busca por um ponto de equilíbrio nas mais diversas relações das pessoas com o seu meio (entendido este em amplo sentido), tem se mostrado como uma necessidade ingente à espera atendimento. É nesse cenário que o termo sustentabilidade aparece, permeando discursos de diversas naturezas, chegando mesmo à sua banalização, em alguns casos.

Não obstante, é perceptível que a sustentabilidade é ainda pouco entendida em sua extensão e rasamente compreendida quanto às suas implicâncias - em especial no Brasil, mesmo quando a realidade mundial das pessoas e das instituições tem dado causa a que se busque conhecer e, mais do que isso, colocar em prática os postulados da sustentabilidade, sob pena de não haver realidade possível a ser discutida posteriormente.

Nesse contexto, o viés mais evidente da sustentabilidade ainda é o da sustentabilidade ambiental, tendo em vista o quadro mundial de descontrole climático e o ingresso em um nível tal de escassez de recursos fundamentais, como água potável, até então não experimentados de forma simultânea por um número tão grande de pessoas no planeta. Em consequência, conflitos e mazelas de toda ordem e amplitude tornaram-se habituais em nossa sociedade, com reflexos em várias esferas da vida humana.

O Direito, como ciência que busca, em última instância, a pacificação das relações sociais, tem voltado sua atenção para essa temática, complexa e multidisciplinar, ampliando a visão a respeito do tema para além das fronteiras do Direito Ambiental. Daí falar-se na atualidade da necessidade de se ter sistemas (dentre outros) administrativos, previdenciários, financeiros, econômicos, de produção sustentáveis. 
Por exemplo, a Lei no 12.187/2010, que trata da Política Nacional de Resíduos Sólidos, no inciso $\mathrm{X}^{1}$ de seu art. 7o de forma textual, assevera que a prestação dos serviços públicos de limpeza urbana e de manejo de resíduos sólidos deve ser dotada de mecanismos gerenciais e econômicos que assegurem a recuperação dos custos dos serviços prestados, como maneira de garantir sua sustentabilidade operacional e financeira.

Essa realidade tem paulatinamente transformado o enfoque que se teve até então a respeito de várias práticas e postulados assentados no cotidiano da Administração Pública. Das mudanças mais perceptíveis, destaca-se o novo contorno dos procedimentos licitatórios, os quais passaram a ter também como perspectiva para a sua correta consecução, a sustentabilidade. Assim sendo, o conjunto normativo hoje existente sobre sustentabilidade, especialmente a ambiental, é considerável - indo de encontro aos acordos internacionais, passando por leis e decretos disciplinadores de diversos institutos, chegando a instruções normativas que visam dar concretude a vários comandos legais.

A par disso, instituições de alta envergadura no Brasil, como o Tribunal de Contas da União (TCU) e o Conselho Nacional de Justiça (CNJ), têm envidados esforços para materializar os discursos de administração pública sustentável em relação aos recursos postos à disposição do Estado. Este é um desafio sem precedentes em razão da finitude dos recursos disponíveis e o crescimento exponencial das necessidades em nossa sociedade.

Em virtude desses fatos, o presente artigo foi escrito com o objetivo de contribuir para a melhor compreensão de tema tão relevante nos dias correntes. Por meio deste ensaio pretende-se, primeiro, prestar esclarecimentos acerca do conceito da sustentabilidade, compreendido para além da sustentabilidade ambiental; segundo, demonstrar como a sustentabilidade, em particular a ambiental, vem modificando a prática cotidiana da Administração Pública sob vários aspectos; terceiro, trazer

\footnotetext{
${ }^{1}$ Art. 7ํ São objetivos da Política Nacional de Resíduos Sólidos: X - regularidade, continuidade, funcionalidade e universalização da prestação dos serviços públicos de limpeza urbana e de manejo de resíduos sólidos, com adoção de mecanismos gerenciais e econômicos que assegurem a recuperação dos custos dos serviços prestados, como forma de garantir sua sustentabilidade operacional e financeira, observada a Lei no 11.445, de 2007. Grifos nossos.
}

Resenha Eleitoral (Florianópolis), v. 20, n. 1, p. 123-152, jul. 2016 
ao conhecimento geral como instituições de grande relevância como o TCU e o CNJ têm encaminhado essa matéria em suas esferas de atuação. Por fim, são apresentadas as conclusões do presente estudo.

O método utilizado para tanto foi o qualitativo, com a revisão bibliográfica da produção científica de alguns dos estudiosos sobre o tema. Nesse tocante, verificou-se que a discussão - da sustentabilidade vista para além dos contornos do Direito Ambiental e inserida em outros contextos, principalmente o jurídico - é recente. Assim, a produção científica a respeito do assunto com mais atenção é ainda diminuta, embora a discussão desse tema esteja em franco crescimento.

É necessário sublinhar que, em razão da vastidão temática, a sua discussão neste ensaio foi direcionada para o debate jurídico sobre o tema, em especial sob os aspectos do Direito Administrativo e do Ambiental, buscando demonstrar, ainda que resumidamente, como se encontra a atual ordem jurídica sob a qual atua o administrador público. Salienta-se, por fim, a importância da exposição desta matéria no âmbito do TCU e do CNJ - o primeiro, por ser a instância constitucional no Brasil de avaliação e controle dos gastos dos recursos da Administração Pública Federal, os quais representam o maior volume de recursos estatais aplicados diretamente na sociedade; o segundo, em razão da progressiva concretude buscada aos preceitos da sustentabilidade aplicada à prática administrativa no âmbito do Poder Judiciário brasileiro.

\section{A Discussão Jurídica do Tema na Atualidade - Aspectos Gerais e Específicos da Sustentabilidade}

A doutrina mais abalizada da atualidade ${ }^{2}$ vem trabalhando para a consolidação de teorização jurídica consolidada acerca da sustentabi-

\footnotetext{
${ }^{2}$ Dentre vários autores destaca-se: FREITAS, Juarez. Sustentabilidade direito ao futuro. 2. ed. São Paulo: Fórum, 2012. COELHO, Saulo de Oliveira Pinto; DE ARAÚJO, André Fabiano Guimarães. A sustentabilidade como princípio constitucional sistêmico e sua relevância na efetivação interdisciplinar da ordem constitucional econômica e social: para além do ambientalismo e do desenvolvimentismo. Revista da Faculdade de Direito - Universidade Federal de Uberlândia - UFU, 2011, v. 39, p. 261-291. DERANI, Chistiane. Direito ambiental econômico. 2. Ed. São Paulo: Max Limonad, 2001. DERANI, Chistiane. Aplicação dos princípios de direito ambiental para o desenvolvimento sustentável. In: TORRES, Heleno Tavieira (org.). Direito tributário ambiental. São Paulo: Malheiros, 2005.
} 
lidade. Vista em um primeiro momento apenas sob a ótica ambiental pois é a faceta que mais facilmente é percebida, tendo ocorrido por meio dela a sua inserção no ordenamento como preceito jurídico -, hoje os estudiosos acordam que se trata de um princípio normativo interdisciplinar de ampla aplicabilidade, que comporta vários aspectos relevantes os quais, por si só, constituem microssistemas normativos podendo-se citar, por exemplo: a sustentabilidade constitucional social, a sustentabilidade constitucional econômica, a sustentabilidade constitucional cultural, a sustentabilidade constitucional político-gerencial e a sustentabilidade constitucional ambiental.

Na base de cada um desses microssistemas está a ideia de equilíbrio, entendido este como uma equação cujo resultado é a satisfação responsável de necessidades presentes e a viabilidade de existência futura digna, com capacidade de manter-se com a maior constância possível (COELHO e ARAÚJO, 2011, p. 6). Nessa perspectiva, exemplificando, segundo Coelho e Araújo (Idem, p. 7; 9-12) a sustentabilidade constitucional econômica reflete-se na busca pelo equilíbrio entre o uso de recursos naturais e a produção de riquezas. Já a sustentabilidade constitucional político-gerencial está relacionada a melhor tomada de decisão para o coletivo social, haja vista que as decisões dessa natureza refletem diretamente no "equilíbrio sistêmico do complexo convívio humano". Basta citar, como exemplo, o impacto que há no direcionamento de uma forma ou de outra dos gastos públicos com saúde ou com mobilidade urbana.

Nesse contexto, a definição de sustentabilidade em uma perspectiva sistêmica, segundo os autores supracitados, mostra-se relacionada à:

[...] continuidade dos aspectos econômicos, políticos, sociais, culturais e ambientais da sociedade humana [devendo, portanto, se basear em cinco alicerces] tendo de ser economicamente viável, politicamente adequado, socialmente justo, culturalmente aceito e ecologicamente correto. (COELHO E ARAÚJO, 2001, p. 5).

Por sua vez, Freitas (2013) traz o seguinte conceito de sustentabilidade: 
[...] a sustentabilidade, no sistema brasileiro, é princípio de estatura constitucional $(\mathrm{CF}$, arts. 3을 $225,170, \mathrm{VI})$, incidente no âmbito do sistema administrativo, de sorte a alterar os seus pressupostos e a se converter na mais provável e expressiva fonte de inovação. O conceito de sustentabilidade, aqui defendido, é o de princípio constitucional que determina, com eficácia direta e imediata, a responsabilidade do Estado e da sociedade pela concretização solidária do desenvolvimento material e imaterial, socialmente inclusivo, durável e equânime, ambientalmente limpo, inovador e ético no intuito de assegurar, no presente e no futuro, o direito fundamental ao bem estar; [...]. [Grifos nossos].

Nesse diapasão, o assento da sustentabilidade como norma jurídica no Brasil é o texto constitucional, pois dele emana a força de sua aplicabilidade sistêmica, transcendendo ao patamar de valor constitucional, materializando-se, assim, como princípio, como normas, leis, regras e preceitos diversos. Na ordem internacional, tratados e normas de toda espécie respeitantes à sustentabilidade multiplicam-se e ganham relevância na medida em que os padrões até agora vigentes de normas que tratam da coexistência humana em seus aspectos mais basilares têm se mostrado débeis e/ou obsoletos, quando não inócuos.

Assim, observa-se que apesar dos múltiplos aspectos inerentes à sustentabilidade, todos convergem para a sua noção fundamental como forma de se alcançar um ponto de equilíbrio, no qual seja possível conciliar os interesses e direitos fundamentais da presente e das futuras gerações. Por isso falar-se na sustentabilidade dos sistemas previdenciário ${ }^{3}$, financeiro, econômico etc., pois estes devem atender não apenas às carências do agora, mas, principalmente, do que está por vir.

Sob este prisma, a sustentabilidade, em particular a ambiental, ganha relevo especial no ordenamento jurídico mundial porquanto de fato, tenham os povos consciência disso ou não, a existência humana está na iminência de vivenciar um de seus piores momentos históricos para a sua sobrevivência, por conta dos desarranjos ambientais (sentidos e percebidos mais de perto pelas drásticas mudanças climáticas já em curso). Tais problemas não são mais projeções de futuro, são questões de

\footnotetext{
${ }^{3}$ Nesse sentido, o TCU lançou uma série de vídeos sobre a sustentabilidade dos sistemas de previdência social que podem ser acessados em $<$ https://www.youtube.com/ watch? $v=$ NswkL_tgp_E $>$.
} 
nosso tempo e que reclamam medidas eficazes e para além dos discursos teóricos.

Por todo esse contexto, a Conferência do Clima realizada em Paris no final de 2015 foi aguardada como evento decisivo do qual se esperava o surgimento um novo marco legal de compromisso entre as nações, a fim de conter os nefastos efeitos que a ainda vigente cultura de consumo e desenvolvimento predatórios ${ }^{4}$ nos trouxe. Por essas razões, a referida conferência teve o aval da Convenção-quadro das Nações Unidas sobre Mudanças Climáticas, e o respaldo das mais importantes autoridades mundiais.

Martin Wolf (2015), comentarista chefe de Economia no jornal britânico Financial Times, participante do Fórum de Davos desde 1999 e

${ }^{4} \mathrm{O}$ consumo inconsequente de produtos ainda é uma característica bastante forte nas últimas gerações. Não apenas se consome muito, como se consome mal e de forma degradante. O uso desenfreado de plásticos e descartáveis, por exemplo, levou pesquisadores da Universidade de Leicester, na Inglaterra, a apresentaram um estudo sobre os efeitos de longo prazo do plástico nos oceanos e no solo (TRIGUEIRO, 2016). Os resultados dessa pesquisa são preocupantes. O comodismo e modismos em geral têm feito com que se acumule uma carga ingente de detritos, vários deles tóxicos, que se acumulam e se alastram pelo solo, pelas águas e pelo ar. As empresas e indústrias ainda se guiam por práticas que não levam em conta de fato a sustentabilidade de seus meios de produção e o impacto de seus produtos na sociedade. As instâncias estatais começam a tomar as primeiras medidas mais efetivas no sentido. Nessa vertente, no Brasil foi editada a Lei no 13.186 , de 11 de novembro de 2015, que instituiu a Política de Educação para o Consumo Sustentável. Pelo texto da lei, o consumo sustentável é entendido como "o uso dos recursos naturais de forma a proporcionar qualidade de vida para a geração presente sem comprometer as necessidades das gerações futuras" - parágrafo único do art. 1․ Não obstante, há iniciativas bem mais ousadas e práticas no mundo, por exemplo, na China que anunciou na COP21, a conferência sobre mudança climática, que vai reduzir consideravelmente suas emissões de carbono. Como bem observa LEMOS (2015), não há altruísmo nessa deliberação. A China assim o faz porque enxerga no cenário atual "uma enorme oportunidade econômica: apostar em tecnologias verdes e em energia limpa, setor que estará em alta nas próximas décadas. O governo chinês vai investir US\$2,5 trilhões ( $\mathrm{R} \$ 9,4$ trilhões) nos próximos 15 anos em energia limpa. A estratégia é promover colaboração entre empresas globais e empresas chinesas, com foco em inovação. É uma lástima que o Brasil não tenha se posicionado com força nesse jogo. Nosso país tem tudo para ser líder nele. Só que a falta de visão - simbolizada pelo encanto com o pré-sal - nos tirou da rota". As nações que se aperceberem dessa nova realidade e as empresas que incorporarem a ideia de sustentabilidade nas suas cadeias produtivas serão as que terão melhores condições de sobreviver em uma realidade cujos estudos mais abalizados apontam que será caracterizada pela limitação ou ausência dos recursos mais básicos, como água potável.

Resenha Eleitoral (Florianópolis), v. 20, n. 1, p. 123-152, jul. 2016 
do Conselho Internacional de Mídia, ao fazer acurada análise sobre o referido evento pondera que, no estágio atual, o acordo resultante de Paris é "[...] muito mais do que o mundo poderia ter esperado razoavelmente um ou dois anos atrás. Mas também é muito menos do que ele precisa”. Isso porque, segundo o articulista:

Como está hoje, na melhor das hipóteses, ele vai abrandar o ritmo em que o mundo chegará a um possível desastre. [...].

As conquistas dos negociadores, presididos habilmente pelo governo francês, estão longe de serem nulas. Elas mostraram que é possível que os países do mundo concordem em torno de uma ação em resposta a um perigo comum, mesmo que ele pareça algo remoto e incerto para muitos dos que vivem hoje. [...]. O que realmente importa não é o acordo de Paris, mas o que vem em seguida. Os planos nacionais devem ser e se tornar ambiciosos rapidamente. O mundo também precisa de um novo padrão de investimento e de novas fontes de financiamento, apoiadas pela troca de incentivos. [...].

Esse acordo foi duramente conquistado. Mas é apenas um pequeno passo, mesmo que na direção certa. É muito cedo para ter certeza de que a curva das emissões vai agora virar decisivamente para baixo. Lao Tsé, o antigo sábio chinês, disse: "Uma longa viagem começa com um único passo."

A questão é se a humanidade tem a vontade ou até mesmo tempo para terminar uma viagem que começou tão tarde. (WOLF, 2015).

Essa necessidade da aplicabilidade dos conceitos da sustentabilidade no campo das decisões políticas de Estado, em especial a ambiental, tendo consequência direta no trato e condução dos atos e procedimentos da Administração Pública, remonta ao posicionamento formal que a Organização das Nações Unidas fez sobre o tema, ainda em 1987, no Relatório "Nosso Futuro Comum", fruto de trabalho desenvolvido pela Comissão Mundial de Meio Ambiente e Desenvolvimento, mais conhecido como Relatório Brundtland.

Após esse marco, outros eventos tendo foco na sustentabilidade foram realizados destacando-se, a Conferência Rio-92, da qual resultou a Agenda 21; e a Rio+20, no qual foi lançado o Programa-Quadro de 10 anos para Consumo e Produção Sustentáveis, que teve como resultado o Programa de Compras Públicas Sustentáveis lançado em abril de 2014 
e capitaneado pelo Programa das Nações Unidas para o Meio Ambiente (PNUMA), com o fito de dar apoio a essa prática nos governos.

O Estado brasileiro, no influxo desses fatos e como partícipe de acordos e tratados internacionais que versam sobre essa matéria, teve significativa modificação em seu ordenamento jurídico, chegando mesmo a ocorrer mudança de paradigma, especialmente no que tange às contratações públicas. A maioria dos agentes públicos e operadores do Direito ainda não perceberam a modificação ocorrida, causando baixa efetividade de várias dessas prescrições legais.

Acerca dessa nova ordem no contexto cotidiano da Administração Pública brasileira, Freitas (2013) acertadamente pondera que:

[...] a sustentabilidade, em consórcio indissolúvel com os demais princípios, vincula, com eficácia negativa, a discricionariedade. No limite, a obra ineficiente, o serviço nefasto e o produto nocivo compõem o quadro de condutas ilícitas, uma vez que violadoras do princípio.

Por outras palavras, não se admite a liberdade contratual para descumprir a função ambiental, social e econômica dos contratos administrativos. Parafraseando o art. 421 do Código Civil, a liberdade de contratação administrativa só poderá ser exercida "em razão e nos limites" da sustentabilidade.

Não obstante os obstáculos existentes há um considerável esforço mundial para que os comandos legais que tratam dessa temática passem para a realidade, ou seja, que o intento benéfico inscrito nas normas seja levado a efeito prático na vida cotidiana das sociedades. Nessa esteira, o ordenamento jurídico brasileiro foi progressivamente evoluindo como é possível observar pelas normas destacadas a seguir:

- 1981 - edição da Lei no 6.983, que estabelece as diretrizes gerais da Política Nacional do Meio Ambiente (LPNMA). Em seu art. 4을 inciso I, é prescrito que a Política Nacional do Meio Ambiente visará à compatibilização do desenvolvimento econômico social com a preservação da qualidade do meio ambiente e do equilíbrio ecológico; 
- 1988 - promulgação da Constituição Federal brasileira que, por seus arts. $225^{5}$ e 170 , VI ${ }^{6}$, dentre outros dispositivos, consagrou o direito ao meio ambiente ecologicamente equilibrado;

- 2009 - edição da Lei no 12.187, que define as diretrizes da Política Nacional da Mudança do Clima (PNMC). Em seu art. 6 ${ }^{\circ}$, inciso XII ${ }^{7}$, prescreveu, como um dos instrumentos da PNMC, o estabelecimento de critérios de preferência nas licitações e concorrências públicas, compreendidas aí as parcerias público-privadas, e a autorização, permissão, outorga e concessão para exploração de serviços públicos e recursos naturais, para as propostas que propiciem maior economia de energia, água e outros recursos naturais e redução da emissão de gases de efeito estufa e de resíduos;

- 2010 - edição da Lei no 12.305, que institui a Política Nacional de Resíduos Sólidos (PNRS), estabelecendo, pelo seu art. 7을 inciso XI, como objetivo da PNRS, a priorização, nas aquisições e contratações governamentais, para produtos reciclados e recicláveis, assim como para bens, serviços e obras que considerem critérios compatíveis com padrões de consumo social e ambientalmente sustentáveis. Este mesmo

5 Art. 225. Todos têm direito ao meio ambiente ecologicamente equilibrado, bem de uso comum do povo e essencial à sadia qualidade de vida, impondo-se ao Poder Público e à coletividade o dever de defendê-lo e preservá-lo para as presentes e futuras gerações.[...]. [Grifo nosso].

${ }^{6}$ Art. 170. A ordem econômica, fundada na valorização do trabalho humano e na livre iniciativa, tem por fim assegurar a todos existência digna, conforme os ditames da justiça social, observados os seguintes princípios: [...]; VI - defesa do meio ambiente, inclusive mediante tratamento diferenciado conforme o impacto ambiental dos produtos e serviços e de seus processos de elaboração e prestação; (Redação dada pela Emenda Constitucional no 42, de 19.12.2003) [Grifo nosso].

7 Art. 6o São instrumentos da Política Nacional sobre Mudança do Clima: XII - as medidas existentes, ou a serem criadas, que estimulem o desenvolvimento de processos $e$ tecnologias, que contribuam para a redução de emissões e remoções de gases de efeito estufa, bem como para a adaptação, dentre as quais o estabelecimento de critérios de preferência nas licitações e concorrências públicas, compreendidas aí as parcerias público-privadas e a autorização, permissão, outorga e concessão para exploração de serviços públicos e recursos naturais, para as propostas que propiciem maior economia de energia, água e outros recursos naturais e redução da emissão de gases de efeito estufa e de resíduos; [Grifo nosso]. 


\section{dispositivo legal traz ainda diversos comandos importantes, todos convergentes ao que se consagrou nominar como de- senvolvimento sustentável ${ }^{8}$;}

8 Art. 7o São objetivos da Política Nacional de Resíduos Sólidos:

I - proteção da saúde pública e da qualidade ambiental;

II - não geração, redução, reutilização, reciclagem e tratamento dos resíduos sólidos, bem como disposição final ambientalmente adequada dos rejeitos;

III - estímulo à adoção de padrões sustentáveis de produção e consumo de bens e serviços;

IV - adoção, desenvolvimento e aprimoramento de tecnologias limpas como forma de minimizar impactos ambientais;

$\mathrm{V}$ - redução do volume e da periculosidade dos resíduos perigosos;

VI - incentivo à indústria da reciclagem, tendo em vista fomentar o uso de matérias-primas e insumos derivados de materiais recicláveis e reciclados;

VII - gestão integrada de resíduos sólidos;

VIII - articulação entre as diferentes esferas do poder público, e destas com o setor empresarial, com vistas à cooperação técnica e financeira para a gestão integrada de resíduos sólidos;

IX - capacitação técnica continuada na área de resíduos sólidos;

$\mathrm{X}$ - regularidade, continuidade, funcionalidade e universalização da prestação dos serviços públicos de limpeza urbana e de manejo de resíduos sólidos, com adoção de mecanismos gerenciais e econômicos que assegurem a recuperação dos custos dos serviços prestados, como forma de garantir sua sustentabilidade operacional e financeira, observada a Lei ํㅡㄴ 11.445 , de 2007;

$\mathrm{XI}$ - prioridade, nas aquisições e contratações governamentais, para: a) produtos reciclados e recicláveis; b) bens, serviços e obras que considerem critérios compatíveis com padrões de consumo social e ambientalmente sustentáveis;

XII - integração dos catadores de materiais reutilizáveis e recicláveis nas ações que envolvam a responsabilidade compartilhada pelo ciclo de vida dos produtos;

XIII - estímulo à implementação da avaliação do ciclo de vida do produto;

XIV - incentivo ao desenvolvimento de sistemas de gestão ambiental e empresarial voltados para a melhoria dos processos produtivos e ao reaproveitamento dos resíduos sólidos, incluídos a recuperação e o aproveitamento energético;

$\mathrm{XV}$ - estímulo à rotulagem ambiental e ao consumo sustentável. [Grifos nossos]. 
- 2011 - edição da Lei no 12.462, que institui o Regime Diferenciado de Contratações Públicas (RDC). O art. $4{ }^{\circ}{ }^{9}$ dessa norma traz preceitos referentes à busca da sustentabilidade sob diversos aspectos - urbanístico (inciso IV); de proteção

\footnotetext{
${ }^{9}$ Art. 4ำ Nas licitações e contratos de que trata esta Lei serão observadas as seguintes diretrizes:
}

I - padronização do objeto da contratação relativamente às especificações técnicas e de desempenho e, quando for o caso, às condições de manutenção, assistência técnica e de garantia oferecidas;

II - padronização de instrumentos convocatórios e minutas de contratos, previamente aprovados pelo órgão jurídico competente;

III - busca da maior vantagem para a administração pública, considerando custos e benefícios, diretos e indiretos, de natureza econômica, social ou ambiental, inclusive os relativos à manutenção, ao desfazimento de bens e resíduos, ao índice de depreciação econômica e a outros fatores de igual relevância;

IV - condições de aquisição, de seguros, de garantias e de pagamento compatíveis com as condições do setor privado, inclusive mediante pagamento de remuneração variável conforme desempenho, na forma do art. 10; (Redação dada pela Lei no 12.980 , de 2014);

$\mathrm{V}$ - utilização, sempre que possível, nas planilhas de custos constantes das propostas oferecidas pelos licitantes, de mão de obra, materiais, tecnologias e matérias-primas existentes no local da execução, conservação e operação do bem, serviço ou obra, desde que não se produzam prejuízos à eficiência na execução do respectivo objeto e que seja respeitado o limite do orçamento estimado para a contratação; e

$[\ldots]$.

$\S 1^{\circ}$ As contratações realizadas com base no RDC devem respeitar, especialmente, as normas relativas à:

I - disposição final ambientalmente adequada dos resíduos sólidos gerados pelas obras contratadas;

II - mitigação por condicionantes e compensação ambiental, que serão definidas no procedimento de licenciamento ambiental;

III - utilização de produtos, equipamentos e serviços que, comprovadamente, reduzam o consumo de energia e recursos naturais;

IV - avaliação de impactos de vizinhança, na forma da legislação urbanística;

$\mathrm{V}$ - proteção do patrimônio cultural, histórico, arqueológico e imaterial, inclusive por meio da avaliação do impacto direto ou indireto causado pelas obras contratadas; e

VI - acessibilidade para o uso por pessoas com deficiência ou com mobilidade reduzida. § O impacto negativo sobre os bens do patrimônio cultural, histórico, arqueológico e imaterial tombados deverá ser compensado por meio de medidas determinadas pela autoridade responsável, na forma da legislação aplicável. [Grifos nossos]. 
ao patrimônio cultural, histórico, arquitetônico e imaterial (inciso V); de acessibilidade (inciso VI) -, a serem observados quando da realização de licitações e contratos sob esse regime. Salienta-se o conteúdo inscrito nos seus incisos I a III e nos $\S \S 1^{\circ}$ e $2^{\circ}$, por trazerem várias prescrições de caráter de apoio à sustentabilidade, não apenas a ambiental. Destaca-se também para o consignado no inciso III, a busca da maior vantagem para a administração pública considerando custos e benefícios, diretos e indiretos, de natureza econômica, social ou ambiental, inclusive os relativos à manutenção, ao desfazimento de bens e resíduos, ao índice de depreciação econômica e a outros fatores de igual relevância, diretriz esta a ser considerada quando da feitura de licitações e contratos dessa natureza, dotando tais procedimentos de racionalidade mais profícua e acordada com a realidade atual.

Nessa evolução legislativa merece especial atenção a Lei $\mathrm{n}^{\mathrm{o}}$ $8.666 / 1993$, em seu art. $3^{\circ}{ }^{10}$, com a redação que lhe foi dada pela Lei $n^{0}$ 12.349/2010, pelo qual ficou expressamente estabelecido que a licitação objetiva, também, a promoção do desenvolvimento nacional sustentável. O Decreto no 7.746/2012, regulamentador desse dispositivo, estabeleceu as diretrizes para o desenvolvimento sustentável nas contratações federais, criou a Comissão Interministerial de Sustentabilidade Pública e definiu, ainda, a obrigatoriedade de elaboração dos Planos de Gestão Sustentável.

Os referidos comandos guardam relação direta com as chamadas contratações públicas sustentáveis, atualmente reconhecidas como um dos principais instrumentos de promoção da sustentabilidade no âmbito da Administração Pública Federal brasileira. Essa mudança na legislação do Brasil, como dito alhures, é resultado do esforço mundial de busca por medidas realistas para o alcance da sustentabilidade nos mais diversos aspectos. O Brasil como signatário de vários tratados internacionais,

10 Art. 3ํㅗ A licitação destina-se a garantir a observância do princípio constitucional da isonomia, a seleção da proposta mais vantajosa para a administração e a promoção do desenvolvimento nacional sustentável e será processada e julgada em estrita conformidade com os princípios básicos da legalidade, da impessoalidade, da moralidade, da igualdade, da publicidade, da probidade administrativa, da vinculação ao instrumento convocatório, do julgamento objetivo e dos que lhes são correlatos. [...].

Resenha Eleitoral (Florianópolis), v. 20, n. 1, p. 123-152, jul. 2016 
e até mesmo para permanecer como partícipe de significativos acordos de repercussão nos negócios públicos e privados, passou a integrar o rol dos governos que utilizam as compras públicas como meio de promover ações consolidadoras da sustentabilidade, em especial a ambiental.

É consabido que as compras governamentais movimentam significativas somas financeiras, chegando a representar, segundo estimativas, de $8 \%$ a $25 \%$ do Produto Interno Bruto (SILVA, 2016) - calcula-se que no Brasil as compras públicas alcançariam o patamar de $10 \%$ do PIB. Essa força econômica direcionada para a adoção de critérios de consumo sustentáveis, segundo os estudiosos, teria repercussão positiva não apenas no setor público - pela modificação no padrão de compras e contratações obrigando a adoção de medidas menos agressivas e mais protetivas do meio ambiente por parte dos fornecedores -, mas também no setor privado, na medida em que esse novo padrão de consumo passa a ser disseminado em toda a sociedade como o "modelo comum/normal" de aquisição de bens e de consumo de produtos.

Essa séria mudança de paradigma está sendo acompanhada por várias dificuldades e discussões: há dúvidas sobre como operacionalizar na prática as contratações sustentáveis; há uma resistência comodista em vários setores; há temores diversos sobre as responsabilidades em se quebrar padrões bastante arraigados na cultura da Administração Pública (como a preferência pela aquisição de produtos que inicialmente mostram-se mais em conta em termos financeiros, porém, que com o passar do tempo, possuem um custo para a sustentabilidade muito alto).

É o que ocorre, por exemplo, na aquisição de equipamentos de tecnologia da informação que não respeitam as regras internacionais de segurança e de sustentabilidade, ao invés de serem adquiridos os chamados equipamentos de "TI Verde", que respeitam as melhores regras de segurança e são compatíveis com os parâmetros da sustentabilidade.

Nesse sentido, a Administração Pública Federal brasileira tem investido em várias ações, como a formação e a disponibilização de bancos de dados sobre produtos, serviços e fornecedores que primam pela sustentabilidade - que podem ser acessados em sítios eletrônicos oficiais como é o caso do ComprasNet ${ }^{11}$, e a edição de normas orientadoras de práticas de sustentabilidade como, por exemplo, a Instrução Normativa

11 Que pode ser acessado no endereço eletrônico < http://cpsustentaveis.planejamento. gov.br>. 
SLTI/MP no $01 / 2010{ }^{12}$ (a qual dispõe sobre os critérios de sustentabilidade ambiental na aquisição de bens, contratação de serviços ou obras pela Administração Pública Federal) e a Instrução Normativa SLTI/MP no 10/2012 ${ }^{13}$ (a qual dispõe sobre os Planos de Gestão e Logística Reversa).

Em suma, não obstante o muito a ser feito, as dificuldades existentes e o obstinado apego a padrões de consumo obsoletos e insustentáveis ainda reinantes, as ações empreendidas até o momento por parte de vários atores do cenário político-internacional têm conseguido influenciar diversas nações a iniciar a modificação de seus padrões de consumo e de vida em busca de maior efetividade da sustentabilidade em seu mais amplo sentido.

O Estado brasileiro, no influxo dessa realidade e como partícipe da ordem internacional que envida esforços no sentido da implementação de um equilíbrio das várias forças atuantes no mercado e na sociedade com vista à sustentabilidade, tem levado a efeito ações que visam integrar a sustentabilidade no cotidiano das práticas da Administração como um todo e da sociedade em geral.

Nessa esteira, instituições de reconhecida importância - como o são o TCU e o CNJ - têm se constituído como agentes singulares na promoção da sustentabilidade como realidade jurídica benéfica e não apenas como discurso retórico. Em rápido panorama, a atuação dessas duas entidades nessa temática será tratada nos dois tópicos seguintes.

\section{O Posicionamento do Tribunal de Contas da União sobre a Matéria}

A sustentabilidade, especialmente a ambiental, passou a ser abordada pelo TCU de forma mais expressa a partir de meados do ano de 2003, conforme pode ser verificado pelo teor dos seguintes julgados daquela Corte de Contas: Acórdão oํ 1.846/2003 e Acórdão 1.852/2003, ambos do Plenário.

\footnotetext{
12 Acessível em:<http://www.comprasnet.gov.br/legislacao/legislacaoDetalhe.asp?ctd$\mathrm{Cod}=295>$.

13 Acessível em: <http://www.mme.gov.br/documents/10584/1154501/Instruxo-Normativa-10-2012.pdf/228ebf79-20dc-4e74-b019-8cc613338>.
}

Resenha Eleitoral (Florianópolis), v. 20, n. 1, p. 123-152, jul. 2016 
Mais adiante, em 2010, constou no Acórdão no 1.260-TCU Segunda Câmara ${ }^{14}$, em sua parte dispositiva, item 9.4, a recomendação de que fosse implementado trabalho específico por parte de equipes técnicas do TCU no sentido de avaliar em que medida as ações adotadas pela Administração Pública nas áreas de redução de consumo próprio de papel, energia elétrica e de água atingiram os objetivos propostos inicialmente (metas fixadas, acompanhamento, ações objetivas e concretas implementadas, marcos legais fixados, perspectivas, dentre outras questões julgadas relevantes pelas referidas unidades técnicas).

Essa determinação resultou na realização de auditoria operacional para a avaliação das ações adotadas pela Administração Pública Federal acerca do uso racional e sustentável de recursos naturais. As conclusões desse trabalho foram consignadas no Acórdão no 1.752/2011-Plenário ${ }^{15}$.

Este julgado, de singular importância, é tido como paradigmático quando se trata de saber o posicionamento do TCU sobre a matéria. E não sem razão. O referido arresto constitui-se em um profundo estudo sobre a realidade da Administração Pública Federal brasileira na temática da sustentabilidade e, em particular, da sustentabilidade ambiental. Dos vários tópicos merecedores de atenção do citado julgado, destacam-se, dada a relevância, os seguintes pontos:

- O uso racional e sustentável de recursos naturais é uma preocupação mundial que tem motivado a cooperação entre os países na busca de padrões de produção e consumo mais sustentáveis e de uma economia de baixo carbono. Um consumo mais racional e eficiente colabora com a redução da pressão sobre os recursos naturais e contribui para a diminuição das emissões de gases de efeito estufa, de forma a mitigar os efeitos das mudanças climáticas. Nesse sentido, a Convenção-Quadro das Nações Unidas sobre Mudança do Clima, a Agenda 21 e o Processo Marrakech definem as diretrizes que os países devem seguir para alcançar uma economia pautada na sustentabilidade. O Brasil, como signatário desses

\footnotetext{
14 Íntegra do referido arresto pode ser encontrada no endereço eletrônico $<$ https://contas.tcu.gov.br/juris/SvlHighLight>.

$15 \mathrm{O}$ inteiro teor desse acórdão pode ser encontrado no endereço eletrônico $<$ https:// contas.tcu.gov.br/juris/SvlHighLight>.
} 
três acordos, e também amparado em amplo arcabouço normativo nacional que trata do tema, assumiu a obrigação de fomentar no país esse novo perfil de desenvolvimento (item 274 do acórdão);

- Os valores despendidos pelo setor público somente com o pagamento de energia e água em 2009, da ordem de R \$ 1,5 bilhão, são capazes de ilustrar tanto a magnitude do poder de compra do Estado como a relevância de sua participação como consumidor de recursos naturais. Com isso, é possível dimensionar a importância do papel fomentador e educativo que o comportamento da Administração Pública tem sobre o mercado e a sociedade (item 276 do acórdão);

- Verifica-se, no entanto, que existe uma grande heterogeneidade quanto à atuação das diversas instituições, em que as ações de uso racional de energia, água e papel são aplicadas em grau muito variado conforme cada recurso natural e cada entidade. Há entidades que praticamente não aplicam medidas de uso racional, e também instituições que apresentam resultados muito positivos e abrangentes advindos da adoção da gestão sustentável. Assim, considerando o alto grau de heterogeneidade das ações de sustentabilidade, aliado à ausência de limitações relevantes para a atuação e ao fato que a gestão administrativa é orientada por prioridades, percebe-se, portanto, que a adoção dessas medidas não é vista como uma prioridade para os gestores (itens 277 e 278 do acórdão);

- Essa situação decorre, principalmente, da falta de um direcionamento claro do Governo Central para que todas as instituições públicas federais tenham atuação proativa em questões de sustentabilidade e uso racional de recursos. Além disso, não há um acompanhamento do desempenho das entidades, evidenciando a falta de transparência da performance das instituições, seja para o Governo Central, seja para a sociedade. Com isso, a ação ou inação dos órgãos não gera repercussões, positivas ou negativas - boas práticas não são fomentadas e a potencial gestão precária não é compelida a melhorar (item 280 do acórdão); 
- Outra questão, refere-se ao baixo nível de institucionalização das ações, ou seja, grande parte das entidades não possui um programa interno institucionalizado e não designou responsáveis para implementar e acompanhar as medidas de uso racional. Campanhas de conscientização, cuja ação depende de um direcionamento institucional, têm sido muito pouco utilizadas nas entidades apesar de serem fundamentais para fomentar uma cultura da sustentabilidade de forma perene. $\mathrm{O}$ resultado observado é a personificação da gestão, na qual as ações são tomadas, ou não, conforme o julgamento particular de cada gestor, muitas vezes não atingindo o pleno potencial existente na entidade. Consequentemente, as medidas são descontínuas, isoladas e não se revestem da devida legitimidade institucional (item 284 do acórdão);

- E ainda, um aumento dos recursos orçamentários pode ser obtido tanto pelo crescimento da arrecadação como também pela gestão estratégica da despesa. Ou seja: é possível obter um incremento orçamentário por meio da racionalização dos gastos (item 287 do acórdão).

Por fim, o referido arresto traz diversas determinações e recomendações em sua parte dispositiva, inclusive determinando o encaminhamento do julgado a várias instâncias administrativas dentre as quais o CJN.

Os julgados mais recentes do TCU mostram que há progressivo avanço no trato dessa matéria, notadamente ao abordar assuntos que são ainda controversos na seara das contratações sustentáveis, como é o caso da relação custo/benefício, como, por exemplo, o disposto no Acórdão no 1.375/2015 - Plenário ${ }^{16}$, segundo o qual:

[...]. É legítimo que as contratações da Administração Pública se adequem a novos parâmetros de sustentabilidade ambiental, ainda que com possíveis reflexos na economicidade da contratação. [Grifo nosso].

\footnotetext{
${ }^{16} \mathrm{O}$ referido julgado pode ser obtido em sua íntegra no endereço eletrônico $<$ https:// contas.tcu.gov.br/juris/Web/Juris/ConsultarTextual2/JurisprudenciaSelecionada.faces>.
} 
Ainda quanto a essa temática, o TCU vem ano a ano, desde 2010, solicitando informações específicas às suas unidades jurisdicionadas acerca da adoção de critérios de sustentabilidade ambiental na aquisição de bens e na contratação de serviços ou obras. Isso se dá por duas formas. Primeiro, por ocasião da apresentação ao TCU do Relatório de Gestão, documento pelo qual todos os entes e unidades submetidas à jurisdição do TCU prestam contas anualmente da gestão dos bens e recursos públicos que estão sob a responsabilidade de cada ente. Segundo, por meio de informações específicas prestadas em Processo de Contas em relação aos entes e às unidades submetidas à jurisdição do TCU previamente selecionados, e cujos responsáveis têm as suas contas julgadas por aquele colegiado - tal procedimento foi ratificado por determinação constante no Acórdão ํㅡำ 1.752/2011 - Plenário, permanecendo em prática na atualidade.

Em conclusão, observa-se que a Corte de Contas da União, no exercício de suas atribuições constitucionais, assumiu seriamente o compromisso de contribuir para a efetivação de ações que venham a dar concretude à sustentabilidade, notadamente a ambiental, na Administração Pública Federal. Por meio de seus julgados e ações de fiscalização, o TCU vem alertando aos administradores públicos e à sociedade em geral para a realidade posta de que a adoção de uma postura de sustentabilidade na gestão da coisa pública não é opção mas cumprimento de preceitos constitucionais e legais de fundamental importância.

Alerta ainda para a necessidade premente de serem adotadas práticas e políticas que assegurem a sustentabilidade como direito, cujos reflexos se fazem sentir no presente e se farão mais ainda no futuro próximo. Sinaliza, contundentemente, que uma gestão baseada na racionalidade de consumo e gastos é necessária sob pena de inviabilização das atuações e medidas mais primárias da Administração.

Por fim, o TCU convoca a todos os atores da gestão pública a se comprometerem com uma gestão de recursos naturais e financeiros mais equilibrados. Nesse contexto, e capitaneando ações de discussão nessa área, o TCU promoveu, no mês de novembro de 2015, o II Seminário Internacional Governança e Desenvolvimento: boas práticas e o papel do 
controle externo ${ }^{17}$, que contou com um painel de abertura composto por autoridades internacionalmente reconhecidas no trato do assunto acerca da "Governança e Desenvolvimento Sustentável".

$\mathrm{Na}$ esteira desses fatos, o CNJ, como ente superior de administração, tem encampando diversas ações que convergem para a efetivação da sustentabilidade no âmbito do Judiciário, notadamente pela aplicação das determinações e recomendações constantes no referido Acórdão n⿳o 1.752/2011-Plenário, como se verificará a seguir.

\section{O Atual Norteamento do Conselho Nacional de Justiça sobre o Assunto}

Nos últimos anos, o Conselho Nacional de Justiça, de forma paulatina e progressiva, passou a incluir dentre as suas ações prioritárias no trato das questões administrativas de ordem interna do Poder Judiciário, o enfoque na implementação de medidas que venham a dar efetividade à sustentabilidade e à sustentabilidade ambiental.

Documento de destaque nesse sentido é a Recomendação CNJ no $11 / 2007$, a qual fixou importante rol de diretrizes e determinações acerca da atuação administrativa do Judiciário brasileiro frente à realidade ambiental hodierna. Partindo de sérias considerações ${ }^{18}$, o $\mathrm{CNJ}$ deliberou por recomendar aos Tribunais brasileiros que:

[...] adotem políticas públicas visando à formação e recuperação de um ambiente ecologicamente equilibrado, além da conscientização dos próprios servidores e jurisdicionados sobre a necessi-

\footnotetext{
17 Maiores informações sobre esse evento podem ser obtidas no endereço eletrônico: $<$ http://portal.tcu.gov.br/dialogo-publico/eventos/ii-seminario-internacional-governanca-e-desenvolvimento-boas-praticas-e-o-papel-do-controle-externo.htm $>$.

18 Considerando a recente discussão mundial sobre o aquecimento global, suas causas e consequências nefastas para a existência de vida no planeta;

Considerando a efetiva influência do Poder Público na atividade econômica nacional, especialmente através das compras necessárias para o bom desenvolvimento de suas atividades e efetiva prestação de serviços ao público em geral;

Considerando que a Administração Pública tem papel preponderante na criação de novos padrões de consumo e produção, na condição de grande consumidora e usuária dos recursos naturais; [...]. [Grifo nosso].
} 
dade de efetiva proteção ao meio ambiente, bem como instituam comissões ambientais para o planejamento, elaboração e acompanhamento de medidas, com fixação de metas anuais, visando à correta preservação e recuperação do meio ambiente. ${ }^{19}$ [Grifo nosso].

Como uma das consequências, essa orientação veio a ter reflexos no planejamento estratégico corporativo de diversos Tribunais, o que se mostra como aspecto positivo inicial; não obstante, as Cortes de Justiça ainda estão a encampar em graus variados as prescrições supramencionadas. Há situações de cumprimento meramente formal das ações recomendadas por alguns órgãos judiciais, mas também o engajamento efetivo por parte de outros entes, a ponto destes transformarem significativamente algumas de suas práticas administrativas passando a pautá-las, prioritariamente, pela sustentabilidade. Como exemplo tem-se o Tribunal de Justiça de Santa Catarina que, dentre muitas ações desenvolvidas há vários anos, instituiu Sistema de Gestão Socioambiental específico que atende a Agenda Ambiental da Administração Pública. ${ }^{20}$

Outra iniciativa positiva nessa seara é a campanha "Quero minha cidade limpa" que é promovida pelo Tribunal Regional Eleitoral de Santa Catarina a cada pleito eleitoral. Por meio dela, os partidos políticos e candidatos são incentivados a entregar o material gráfico restante após a realização da eleição diretamente nos cartórios eleitorais, sem custos. Todo o material recolhido é destinado a entidades que trabalham com reciclagem.

A partir desta ação da Justiça Eleitoral catarinense, múltiplos benefícios são implementados, como a prevenção de danos e prejuízos

\footnotetext{
19 Tais como, cita a referida Recomendação, por exemplo: a) utilização de papel reciclado e não clorado nos impressos do Poder Judiciário, sejam de natureza administrativa ou processual; b) instituição da coleta seletiva de resíduos, destinando recipientes individuais para plástico, papel, metal e vidro, e a ulterior doação do material coletado a entidades assistenciais que se responsabilizem pela correta utilização do material para a devida reciclagem; c) aquisição de impressoras que imprimam, automaticamente, em frente e verso; d) aquisição de bens e materiais de consumo que levem em consideração o tripé básico da sustentabilidade: ambientalmente correto, socialmente justo e economicamente viável; e) utilização sustentável da energia e dos combustiveis; e f) utilização de edifícios com observância da proteção ao meio ambiente. [Grifo nosso].

20 Disponível em: < http://www.tjsc.jus.br/web/servidor/sustentabilidade?inheritRedirect $=$ true $>$.
}

Resenha Eleitoral (Florianópolis), v. 20, n. 1, p. 123-152, jul. 2016 
ambientais pelo impedimento de saturação das vias de escoamento de águas pluviais em razão de papéis espalhados pelas ruas, o incremento na geração de renda de entidades que trabalham com reciclagem, assim como a fomentação da consciência de cidadania e cuidado para com os espaços públicos por se evitar os nominados "derrames de santinhos" às vésperas do dia das eleições. Segundo dados da imprensa, nas eleições de 2014 a Companhia de Melhoramentos da Capital (COMCAP) recolheu 9,5 toneladas de "santinhos" nas ruas de Florianópolis após as eleições. ${ }^{21}$

Cônscio de todo esse quadro situacional, e em atenção aos termos do citado Acórdão TCU no 1.752/2011 - Plenário, o CNJ procedeu à edição da Resolução no 201, de 03/03/2015, a qual dispõe sobre a criação e as competências das unidades ou núcleos socioambientais nos órgãos e conselhos do Poder Judiciário, e a implantação do respectivo Plano de Logística Sustentável (PLS-PJ).

A elaboração do documento levou em conta os principais referenciais normativos pertinentes à matéria - como o art. 170, VI, da Constituição Federal; o art. 3o da Lei no 8.666/1993; as Leis no 12.187/2009, n⿳0 12.305/2010, e no $11.419 / 206$, dentre outras.

Foi igualmente considerado o teor do sobredito Acórdão $\mathrm{n}^{0}$ $1.752 / 2011$ e o reconhecimento da

efetiva influência do Poder Público na atividade econômica nacional, especialmente por meio das contratações necessárias para o bom desenvolvimento de suas atividades e efetiva prestação de serviços ao público em geral e a importância de ações planejadas e

${ }_{21}$ Notícia publicada no sítio eletrônico $<$ http://g1.globo.com/sc/santa-catarina/eleicoes/2014/noticia/2014/10/95-toneladas-de-santinhos-sao-recolhidas-em-florianopolis. html>. 
continuadas ligadas à mobilização e sensibilização para questões socioambientais no âmbito do Poder Judiciário. ${ }^{22}$

Com efeito, por meio dessa Resolução, o Poder Judiciário sinaliza seu comprometimento com a efetivação de ações convergentes à

22 CONSIDERANDO o disposto no artigo 170, VI, da Constituição da República Federativa do Brasil, que trata da defesa do meio ambiente, inclusive mediante tratamento diferenciado conforme o impacto ambiental dos produtos e serviços e de seus processos de elaboração e prestação; bem como artigo 225 que estabelece que todos têm direito ao meio ambiente ecologicamente equilibrado;

CONSIDERANDO o disposto no artigo 3ํㅡㄹ Lei 8.666, de 21 de junho de 1993, que cuida das normas para licitações e contratos da Administração Pública e Decreto 7.746, de 5 de junho de 2012, [...];

CONSIDERANDO a Lei 12.187, de 29 de dezembro de 2009, que instituiu a Política Nacional de Mudança de Clima, com diretrizes ao estímulo e apoio à manutenção e promoções de padrões sustentáveis de produção e consumo e como um de seus instrumentos à adoção de critérios de preferência nas licitações e concorrências públicas para as propostas que propiciem maior economia de energia, água e outros recursos naturais e a redução da emissão de gases de efeito estufa e de resíduos; e o disposto na Lei 12.305, de 2 de agosto de 2010, que institui a Política Nacional de Resíduos Sólidos e Decreto 7.407, que regulamenta a supracitada Lei;

$[\ldots]$

CONSIDERANDO as Recomendações CNJ 11/2007 e 27/2009, que tratam da inclusão de práticas de socioambientais nas atividades rotineiras dos tribunais e a necessidade de atualizá-la no PJe;

CONSIDERANDO os modelos de boas práticas de gestão sustentável do Poder Executivo, constantes das Instruções Normativas CNJ 1/2010; 10/2012, que estabelecem regras para elaboração dos Planos de Gestão de Logística Sustentável de que trata o art. 16 do Decreto 7.746, de 5 de junho de 2012; e 2, de 4 de junho de 2014, o qual dispõe sobre a economia de energia nas edificações públicas;

CONSIDERANDO as recomendações do Tribunal de Contas da União, dispostas no Acórdão 1752, de 5 de julho de 2011, que trata das medidas de eficiência e sustentabilidade por meio do uso racional de energia, água e papel adotadas pela Administração Pública;

CONSIDERANDO a efetiva influência do Poder Público na atividade econômica nacional, especialmente por meio das contratações necessárias para o bom desenvolvimento de suas atividades e efetiva prestação de serviços ao público em geral e a importância de ações planejadas e continuadas ligadas à mobilização e sensibilização para questões socioambientais no âmbito do Poder Judiciário; [Grifo nosso]. 
sustentabilidade, e não apenas à ambiental ${ }^{23}$, embora esta mereça espe-

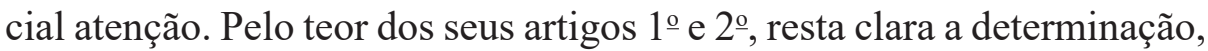
primeiro, de criação nos órgãos integrantes do Poder Judiciário de unidades ou núcleos socioambientais que, no exercício de suas competências, devem implantar o respectivo Plano de Logística Sustentável (PLS-PJ). E, segundo, a determinação de que sejam adotados modelos de gestão organizacional e de processos estruturados na promoção da sustentabilidade ambiental, econômica e social.

Destaque para as contratações sustentáveis que, na referida re-

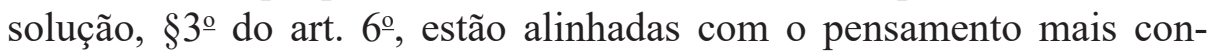
temporâneo sobre a matéria, porquanto sua promoção deverá observar a integração dos aspectos ambientais, econômicos e sociais do desenvolvimento sustentável.

Do exame da mencionada Resolução percebe-se que seu norteamento maior, adotado pelo $\mathrm{CNJ}$, foi as orientações consignadas no Acórdão TCU nº 1.752/2011 - Plenário, porquanto:

(a) o PLS - PJ é considerado como instrumento vinculado ao planejamento estratégico do Poder Judiciário - com objetivos e responsabilidades definidas, ações, metas, prazos de execução, mecanismos de monitoramento e avaliação de resultados - que permite estabelecer e acompanhar práticas de sustentabilidade, racionalização e qualidade que objetivem uma melhor eficiência do gasto público e da gestão dos processos de trabalho, considerando a visão sistêmica do órgão. Ou seja, o fito é tornar o Plano de Logística Sustentável algo factível e apto a colaborar realmente com a efetivação da sustentabilidade - art. 10 da citada Resolução;

(b) as unidades ou núcleos socioambientais deverão ter caráter permanente para o planejamento, implementação, monitoramento de metas anuais e avaliação de indicadores de desempenho para o cumprimento do previsto na citada Resolução - art. 4º da Resolução;

(c) busca-se dar transparência à sociedade das ações de sustentabilidade a serem levadas a efeito por cada PLS, que deverá ser elabo-

${ }_{23} \mathrm{O}$ que pode ser nitidamente percebido pelo teor do $\S 70$, do art. 6o da referida Resolução, segundo o qual, in litteris: "A qualidade de vida no ambiente de trabalho deve compreender a valorização, satisfação e inclusão do capital humano das instituições, em ações que estimulem o seu desenvolvimento pessoal e profissional, assim como a melhoria das condições das instalações fisicas". [Grifo nosso]. 
rado e publicado no sítio dos respectivos órgãos e conselhos do Poder Judiciário, em prazo determinado - art. 21 da Resolução. Em mesmo sentido é o disposto nos arts. 22,23 e $24{ }^{24}$;

(d) busca pela formação e consolidação da cultura de sustentabilidade, haja vista que as iniciativas de capacitação afetas a esse tema deverão ser incluídas no plano de treinamento de cada órgão do Poder Judiciário. E as atividades de ambientação de novos servidores e colaboradores deverão difundir as ações sustentáveis praticadas, de modo a consolidar os novos padrões de consumo consciente do órgão - art. 19 da Resolução.

Em suma, o CNJ, com a edição da Resolução no 01/2015, toma para si a responsabilidade de tornar o Poder Judiciário brasileiro em importante protagonista e colaborador do esforço das principais instituições mundiais, tornando factível um mundo sustentável. Um lugar onde vivência e convivência sejam equilibradamente possíveis.

24 Art. 22. Os resultados obtidos a partir da implantação das ações definidas no PLS-PJ deverão ser publicados ao final de cada semestre do ano no sítio dos respectivos conselhos e órgãos do Poder Judiciário, apresentando as metas alcançadas e os resultados medidos pelos indicadores.

Art. 23. Ao final de cada ano deverá ser elaborado por cada órgão e conselho do Poder Judiciário relatório de desempenho do PLS-PJ, contendo:

I - consolidação dos resultados alcançados;

II - a evolução do desempenho dos indicadores estratégicos do Poder Judiciário com foco socioambiental e econômico, de acordo com o previsto no Anexo I;

III - identificação das ações a serem desenvolvidas ou modificadas para o ano subsequente.

$\S 1^{\circ}$ Os relatórios deverão ser publicados no sítio dos respectivos órgãos e conselhos do Poder Judiciário, e encaminhados, em forma eletrônica, ao CNJ até o dia 20 de dezembro do ano corrente pela autoridade competente do órgão ou conselho.

§2 O DPJ disponibilizará aos órgãos e conselhos do Poder Judiciário acesso ao sistema informatizado para compilação das informações quanto ao PLS-PJ com o objetivo de padronizar o envio e recebimento de dados e facilitar a análise dos indicadores que avaliarão o índice de sustentabilidade das instituições.

Art. 24. O PLS-PJ irá subsidiar, anualmente, o Balanço Socioambiental do Poder Judiciário, a ser publicado pelo CNJ por intermédio do DPJ, no prazo de 180 dias a contar do recebimento do relatório de desempenho dos órgãos. 


\section{Conclusão}

Em vista de todo o exposto, como resultados da pesquisa empreendida, alinham-se as seguintes notas conclusivas:

I. a ciência jurídica vem ampliando a discussão que faz acerca da sustentabilidade, identificando que sua aplicabilidade vai para além das fronteiras do Direito Ambiental. Os estudos empreendidos nessa área convergem no sentido de que a sustentabilidade é reconhecida na atualidade como princípio normativo interdisciplinar de ampla aplicabilidade, no qual estão insertos vários aspectos de relevância que, por si só, constituem microssistemas normativos - como, por exemplo, a sustentabilidade social, a sustentabilidade econômica, a sustentabilidade cultural, a sustentabilidade político-gerencial e a sustentabilidade ambiental;

II. o fundamento da sustentabilidade como norma jurídica, notadamente no Brasil, é o texto constitucional, pois dele emana a força de sua aplicabilidade sistêmica, a qual transcende o patamar de valor constitucional, materializando-se como princípio, normas, leis, regras e preceitos diversos;

III. em virtude das graves transformações climáticas que estão em curso, e que acarretam problemas de grande magnitude, a sustentabilidade focada sob o viés ambiental tem ganhado maior notoriedade midiática, e em razão da qual estão sendo envidados esforços mundiais com vistas a assegurar um ambiente dotado de um mínimo de equilíbrio para existência digna da presente e das futuras gerações;

IV. como resultante desses esforços, na atualidade, os sistemas jurídicos internacional e brasileiro estão sendo dotados de normas das mais variadas espécies, capazes de instrumentalizar ações efetivas para a consecução da sustentabilidade, notadamente a ambiental, no âmbito das sociedades;

V. particularmente no Brasil, as chamadas licitações sustentáveis foram elevadas ao patamar de instrumentos que possuem respaldo legal para introduzir nova cultura administrativa pautada por práticas sustentáveis. O conjunto normativo em torno desse tema é tal que as licitações sustentáveis devem ser consideradas como obrigação do gestor público, e não como opção deste; 
VI. nesta esteira, o Tribunal de Contas da União, no cumprimento de suas atribuições constitucionais, tem envidado esforços no sentido de fomentar a discussão sobre a temática da sustentabilidade, assim como tem promovido ações objetivando à implementação da cultura de sustentabilidade no âmbito da Administração Pública Federal, na qual a concretização de medidas sustentáveis sejam consectários inerentes ao cumprimento do ordenamento jurídico vigente. Para isso o TCU tem promovido auditorias, editado normativos, realizado eventos e pronunciando-se assertivamente em julgados nos quais questões dessa seara são abordadas;

VII. em relação à temática da sustentabilidade, especialmente a ambiental, o Tribunal de Contas da União exarou seu posicionamento vigente no Acórdão nํㅜ 1.752/2011 - Plenário, que é paradigmático quanto a esse assunto. Nele ficou assentado, em suma, que a busca pela sustentabilidade no setor público é um dever decorrente do cumprimento dos princípios basilares da Administração, assim como do atual ordenamento jurídico;

VIII. o Conselho Nacional de Justiça, como órgão de Administração Superior do Judiciário editou a Resolução no 201/2015, a qual dispõe sobre a criação e as competências das unidades ou núcleos socioambientais nos órgãos e conselhos do Poder Judiciário, e implantação do respectivo Plano de Logística Sustentável (PLS-PJ), através do qual assume o papel de protagonista da promoção e efetivação da cultura de sustentabilidade no âmbito do Poder Judiciário brasileiro;

IX. em que pese as dificuldades e os desafios, a discussão e a promoção da sustentabilidade em todos os seus aspectos é medida de necessidade, sob pena de haver drástica ruptura das condições mínimas de vivência e convivência social. Analisados os dados hoje disponíveis acerca da degradação ambiental e das graves mudanças climáticas já sentidas nas mais diversas partes do mundo, percebe-se o quanto um tema cercado de inúmeras obviedades (como a necessidade de se legar às próximas gerações condições mínimas de sobrevivência) seja tão difícil de ser compreendido. O Direito, que como ciência busca, em última instância, a pacificação social, tem ainda árduo caminho por diante;

$\mathrm{X}$. neste contexto, um dos maiores desafios atuais do Direito seja, possivelmente, o de desenvolver uma teorização consistente acerca da sustentabilidade para além da seara ambiental, tornando, assim, 
perceptível e realizável sistema normativo que atenda aos desafios de sobrevivência mínima e digna dos tempos correntes.

\section{Referências}

AMORIM, Patrícia. Para além da licitação sustentável. In: BLIACHERIS, Marcos Weiss; FERREIRA, Maria Augusta Soares de Oliveira (Coord.).

Sustentabilidade na Administração Pública: valores e práticas de gestão socioambiental. Belo Horizonte: Fórum, 2012, p. 277-286.

AZEVEDO, Pedro Henrique Magalhães. Os Tribunais de Contas brasileiros e as licitações sustentáveis. Revista Brasileira de Direito Público - RBDP, Belo Horizonte, v.12, n.47, p. 159-184, out./dez. 2014.

BLIACHERIS, Marcos Weiss. A sustentabilidade no Regime Diferenciado de Contratações Públicas. Fórum de Contratação e Gestão Pública - FCGP, Belo Horizonte, ano 13, n. 145, p. 56-64, jan. 2014.

BREUS, Thiago Lima. Políticas públicas no Estado Constitucional: problemática da concretização dos Direitos Fundamentais pela Administração Pública contemporânea. Belo Horizonte: Fórum, 2007.

COELHO, Saulo de Oliveira Pinto; MELLO, Rodrigo Antonio Calixto. A sustentabilidade como um direito fundamental: a concretização da dignidade da pessoa humana e a necessidade de interdisciplinaridade do direito. Veredas do Direito, v.8, n.15, p. 9-24, jan. 2011.

COELHO, Saulo de Oliveira Pinto; DE ARAÚJO, André Fabiano Guimarães. A sustentabilidade como princípio constitucional sistêmico e sua relevância na efetivação interdisciplinar da ordem constitucional econômica e social: para além do ambientalismo e do desenvolvimentismo. Revista da Faculdade de Direito-Universidade Federal de Uberlândia - UFU, 2011, v. 39, n. 1, p. 261-291.

DERANI, Chistiane. Direito ambiental econômico. 2. Ed. São Paulo: Max Limonad, 2001.

. Aplicação dos princípios de direito ambiental para o desenvolvimento sustentável. In: TORRES, Heleno Tavieira (org). Direito tributário ambiental. São Paulo: Malheiros, 2005.

FERRAZ, Luciano. Função regulatória da licitação. Biblioteca Digital Revista de Direito Administrativo \& Constitucional - A\&C, Belo Horizonte, ano 9, n. 37, jul./set. 2009. 
FERREIRA, Daniel; FILHO MACIEL, Fernando Paulo da Silva. A funcionalização das licitações e contratos administrativos com vistas à promoção do desenvolvimento nacional sustentável. Artigo. Disponível em: $<\mathrm{http}: / /$ www.publicadireito.com.br/artigos/?cod=0cbed40c0d920b94>. Acesso em: 20 jan.2016.

FERREIRA, Daniel; GIUSTI, Anna Flávia Camilli Oliveira. A licitação pública como instrumento de concretização do direito fundamental ao desenvolvimento nacional sustentável. Revista de Direito Administrativo \& Constitucional, Belo Horizonte, v.12, n.48, p. 177-193, abr./jun., 2012.

FERREIRA, Maria Augusta Soares de Oliveira (Coord.). Sustentabilidade na Administração Pública: valores e práticas de gestão socioambiental. Belo Horizonte: Fórum, 2012, p. 83-105.

FREITAS, Juarez. Sustentabilidade direito ao futuro. 2. ed. São Paulo: Fórum, 2012. . Sustentabilidade dos contratos administrativos. Revista de Direito Administrativo e Constitucional - A \& C. Belo Horizonte, Fórum; ano 13, n. 52, abr/jun, 2013.

LEMOS, Ronaldo. Apostar em inovação verde. Artigo. Disponível em: $<$ http://www1.folha.uol.com.br/colunas/ronaldolemos/2015/12/1715775-apostar-em-inovacao-verde.shtml>. Acesso em: 7 dez. 2015.

MOREIRA NETO, Diogo de Figueiredo. Quatro paradigmas do direito administrativo pós-moderno: legitimidade; finalidade; eficiência e resultado. Belo Horizonte: Fórum, 2008.

SARMENTO, Daniel. A ponderação de interesses na Constituição Federal. Rio de Janeiro: Lumen Juris, 2002.

SILVA, Renato Cader da. Compras compartilhadas sustentáveis. Artigo, 2016. Disponível em: <http://www.comprasgovernamentais.gov.br/paginas/ artigos/compras-compartilhadas-sustentaveis>. Acesso em: 10 fev. 2016.

TRIGUEIRO, André. Terra está entrando na Era do Plástico. Artigo. Disponível em: $<$ http://www.mundosustentavel.com.br/2016/02/terra-esta-entrando-na-era-do-plastico/>. Acesso em: 11 fev. 2016.

VIEIRA, André Luís. As contratações públicas sustentáveis na realidade brasileira. Revista Brasileira de Direito Público - RDDP, Belo Horizonte, ano 13, n. 48, p. 21-41, jan./mar. 2015. 


\section{WORLD COMMISSION ON ENVIRONMENT AND DEVELOPMENT}

(WCED). Our common future: report of the world commission on environment and development. Oxford: Oxford University, 1987.

\section{WOLF, Martin. Acordo de Paris sobre o clima é um pequeno passo} para a humanidade. Artigo. Disponível em: $<$ http://www1.folha.uol.com. br/colunas/martinwolf/2015/12/1719771-acordo-de-paris-e-um-pequeno-passo-para-a-humanidade.shtml>. Acesso em: 16 dez. 2015.

Karine Borges de Liz - Analista Judiciário do TRESC, pós-graduada em nível de especialização em Direito Administrativo pela Universidade Regional de Blumenau FURB.

Raulino Jacó Brüning - Doutor em Direito pela Universidade Federal de Santa Catarina - UFSC, Desembargador do Tribunal de Justiça do Estado de Santa Catarina. 